\title{
Effect of the Percentage Body Fat on Muscular Endurance of Junior Free Style Wrestlers
}

\author{
Parwinder Singh and Ashok Kumar
}

\begin{abstract}
Aim: The aim of this study was to observe effect of the percentage body fat on muscular endurance of junior free style wrestlers according to their weight categories. Method: one hundred fifty $(\mathrm{N}=150)$ male junior free style wrestlers were participated as subjects and they were further divided into five groups according to their weight categories, each group was comprised of thirty wrestlers. Body fat percentage was estimated by using Durnin and Womersley equation, In Push up test, recorded the number of push-ups performed in 1 minute. Results: Percentage body fat was found negative relationship with muscular endurance. Conclusion: it is concluded that the free style wrestling is a weight classified sport; therefore the correlation of body composition of the wrestlers with muscular endurance is important. The results of the present study also demonstrated the effect of age, height, weight, $\mathrm{BF} \%$ on the muscular endurance of junior free style wrestlers.
\end{abstract}

Dr. Parwinder Singh

Assistant Professor \& Head

Department of Physical Education

RIMT University, Mandi Gobindgarh (Punjab) India

E-mail: parwindersingh@ rimt.ac.in

Dr. Ashok Kumar

Associate Professor \& Head

Department of Sports Science

Punjabi University Patiala (Punjab) India
Key Words: Free style, Wrestling, Anthropometry, Muscular Endurance, Fat Percentage, Push-up

DOI: $10.18376 / j e s p / 2018 / v 14 / i 1 / 111289$

\section{Introduction}

A sport of wrestling has a strong tradition that precedes the first Olympic festival in 776 B. C., when Zeus wrestled Kronas for the possession of the earth (Gallagher, 1951). In the ancient Olympic Games wrestling was an important part and is still one of the most popular events of the modern Olympic Games. Nowadays, in the Olympics, two wrestling styles, first is Greco-Roman, a classic style in which only upper body moves are allowed and the participants are not allowed to apply the leg techniques, and second is Freestyle, in which upper and lower body techniques are allowed. Both wrestling styles are based on a weight class system, so weight categories are defined in which the different participants participate. The aim of the weight categories is to protect the competitors' health, limiting as much as possible the risk of injuries, as well as balancing out the physical characteristics between wrestlers and therefore increasing the performance percentage that depends on technical, tactical and psychological skills (Hubner et. al., 2004). Since then the sport of wrestling continues to grow in popularity because of the discipline and mental toughness it requires to be successful in the sport. Unfortunately, the sport has also been associated with the stigma of "cutting weight" and the practices that accompany the process of competing at designated weight classes. Like the sports of judo, boxing, and competitive weight lifting, wrestling requires its athletes to compete at specific weights or weight classifications. Typically, these weight classifications differ by approximately 7-11 pounds depending on age and style of wrestling. It is common knowledge in present day of wrestling that wrestlers compete in weight classes below their "normal" weight. The purpose of this practice is to gain advantages in strength, speed, and leverage 


\section{Journal of Exercise Science \& Physiotherapy, Vol. 14, No. 1 (January to June), 2018 ISSN: 0973-2020 (Print) I I OR Impact Factor = 5.23 UGC Approved [no.7485] ISSN: 2454-6089 (Online)}

over their opponents (Steen \& Brownell, 1990). The changes in regulation of wrestling have forced several modifications in the fitness requirements of successful wrestlers, which as a result caused an evolution in the training methods (Yoon 2002; Horswill 1992; Sharratt et. al., 1986).Wrestling has been described as an intermittent physical event which produces great strength and muscle power demands of both the upper and lower body (Hubner-Wozniak et. al. 2004; Kraemer et. al. 2001; Horswill et. al. 1992; Sharratt et. al. 1986). They generally want to minimize the body fat level and the total body weight without losing their body strength and power (Yoon, 2002). However, no relation was shown between the percentage of fat mass $(\% \mathrm{FM})$ and the level of wrestling success (Yoon, 2002; Horswill 1992). In modern wrestling training, physical, technical, and tactical components are indispensable parts of the preparation and competition periods. The main objectives of the training are to increase the wrestler's physiological potential and to develop muscular strength and endurance to the highest standards with exercise. During the preparation or competition periods, the ratio of physical and technical or tactical training depends on the wrestler's age group (cadet, junior, and senior) and level. Strength, Muscular endurance, speed and flexibility are the main components of the physical training during the preparation period (Yoon, 2002 and Horswill, 1992). The aim of the present study was to observe effect of the percentage body fat on muscular endurance of junior free style wrestlers.

\section{Material and Methods}

The study was conducted on 150 male junior free style wrestlers (age between 18-20 years) of five different groups i.e. Group 1: 46-50 kg ; Group 2: $55 \mathrm{~kg}$; Group 3: 60kg ; Group 4: 66kg ; Group 5: $74 \mathrm{~kg}$. The aim of the study was explained to each participant and signed informed consent was obtained from the participants. The \% Body fat of junior free style wrestlers was estimated as per the method described by Durnin and Womersley (1974). In Push-up test, the number of push-ups performed by the wrestler in 1 minute was recorded. Karl Pearson's coefficient of correlation was used to find the relationship among age, weight, and \% Body fat and push-ups variables of free style junior wrestler in five groups according to their weight. To determine the differences between the mean of the various variables among different groups, one way Analysis of Variance (ANOVA) was used. The level of significance was $\mathrm{p}<0.05$.

Table 1. Mean \pm SD of age, height, weight, \% Body fat and push-ups of different groups

\begin{tabular}{lcccccc}
\hline Variable(s) & $\begin{array}{c}\text { Group 1 } \\
(\mathbf{n = 3 0})\end{array}$ & $\begin{array}{c}\text { Group 2 } \\
(\mathbf{n = 3 0})\end{array}$ & $\begin{array}{c}\text { Group 3 } \\
(\mathbf{n = 3 0})\end{array}$ & $\begin{array}{c}\text { Group 4 } \\
(\mathbf{n = 3 0})\end{array}$ & $\begin{array}{c}\text { Group 5 } \\
(\mathbf{n = 3 0})\end{array}$ & $\begin{array}{c}\text { Combined } \\
\text { Group } \\
(\mathbf{n = 1 5 0})\end{array}$ \\
\hline Age (year) & $18.13 \pm 0.77$ & $18.73 \pm 0.69$ & $18.53 \pm 0.68$ & $18.50 \pm 0.68$ & $18.67 \pm 0.47$ & $18.51 \pm .0 .65$ \\
Height (cm) & $166.69 \pm .2 .62$ & $168.00 \pm .2 .62$ & $168.46 \pm .3 .24$ & $168.95 \pm .2 .79$ & $171.80 \pm 4.37$ & $168.78 \pm .3 .12$ \\
Weight (kg) & $51.50 \pm .1 .33$ & $55.70 \pm .1 .41$ & $61.50 \pm 0.88$ & $66.33 \pm .1 .40$ & $74.25 \pm 3.22$ & $61.85 \pm 1.64$ \\
\% Body fat & $9.10 \pm 1.67$ & $10.32 \pm 2.13$ & $11.92 \pm 1.43$ & $12.71 \pm 2.28$ & $14.88 \pm 3.06$ & $11.78 \pm 2.11$ \\
Push ups & $54.10 \pm 6.55$ & $50.40 \pm 8.01$ & $45.26 \pm 5.16$ & $44.40 \pm 4.85$ & $43.90 \pm 4.26$ & $47.61 \pm 5.76$ \\
\hline
\end{tabular}

\section{Results}

Table 1 shows that the mean age of group1, group2, group3, group4, group5 and combined group was 18.13 \pm .77 year, $18.73 \pm .69$ year, $18.53 \pm .68$ year, $18.50 \pm .68$ year, $18.67 \pm .47$ year and $18.51 \pm .0 .65$ years. The mean height of the subjects of group1, group2, group3, group4, group5 and combined group was $166.69 \pm .2 .62 \mathrm{~cm}$ year, $168.00 \pm .2 .62 \mathrm{~cm}, 168.46 \pm .3 .24 \mathrm{~cm}, 168.95 \pm .2 .79 \mathrm{~cm}$, $171.80 \pm 4.37 \mathrm{~cm}$ and $168.78 \pm .3 .12 \mathrm{~cm}$. The mean weight of the subjects of group1, group2, group3, group4, group5 and combined group was $51.50 \pm .1 .33 \mathrm{~kg}, 55.70 \pm .1 .41 \mathrm{~kg}, 61.50 \pm .88 \mathrm{~kg}, 66.33 \pm .1 .40$ $\mathrm{kg}, \quad 74.25 \pm 3.22 \mathrm{~kg}$ and $61.85 \pm 1.64 \mathrm{~kg}$. The mean percent fat of the subjects of group1, group2, 


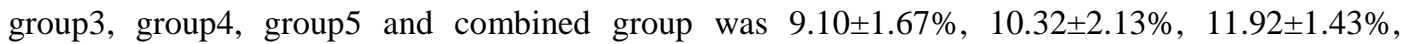
$12.71 \pm 2.28 \%, 14.88 \pm 3.06 \%$. and $11.78 \pm 2.11$. The mean Shuttle run of the subjects of group1, group2, group3, group4 group5 and combined group was $11.62 \pm 0.96,11.74 \pm 0.87,11.92 \pm 1.05$, $12.06 \pm 1.00,12.33 \pm 1.40$ and $11.93 \pm 1.05$. The mean push- ups of the subjects of group1, group2, group3, group4, group5 and combined group was 54.10 $\pm 6.55,50.40 \pm 8.01,45.26 \pm 5.16,44.40 \pm 4.85$, $43.90 \pm 4.26$ and $47.61 \pm 5.76$. Further, the analysis of variance revealed that the variance in the mean values of age, height, weight, \% Body fat and push-ups of junior free style wrestlers among different groups was statistical significant (Table 2).

Table 2. Analysis of variance of age, height, weight, \% Body fat and push-ups among different groups

\begin{tabular}{lccccc}
\hline Variable(s) & Groups & Sum of Squares Mean Square & F & Sig. \\
\hline Age & Between Groups & 6.50 & 1.627 & 3.63 & .008 \\
& Within Groups & 64.96 & .448 & & \\
\hline Height & Between Groups & 427.42 & 106.855 & 10.43 & .000 \\
& Within Groups & 1484.95 & 10.241 & & \\
\hline Weight & Between Groups & 9562.39 & 2390.600 & 706.97 .000 \\
& Within Groups & 490.31 & 3.381 & & \\
\hline Percentage Fat Between Groups & 594.57 & 148.644 & 30.86 & .000 \\
\hline \multirow{5}{*}{ Push-ups } & Within Groups & 698.32 & 4.816 & \\
\hline & Between Groups & 2383.907 & 595.977 & 16.966 .000 \\
& Within Groups & 168.029 & 1.159 & & \\
\hline
\end{tabular}

Table 3 shows a highly statistical significant negative relationship between the percent body fat and push-ups of combined group $(\mathrm{N}=150)$ of junior free style wrestlers.

Table 3. Correlation among \% Body fat and push ups of combined group

\footnotetext{
\begin{tabular}{cc}
\hline Variable(s) & Push-ups \\
\hline$\%$ Body fat & $-.454^{* *}$ \\
\hline *significant at the 0.05 level
\end{tabular}

Discussion

The results of the present study shows that the mean body fat percentage of the junior free style male wrestlers of different groups was in range of 9 to $15 \%$ and it was in the acceptable range when we compared it with values of body fat percentage for wrestlers as reported by Asker and Michael (2010). Asker and Michael (2010) reported the preferred acceptable range of body fat percentage of wrestlers between 5 to $16 \%$. In other words, we can say no obesity was observed in junior free style male wrestlers of different groups of the present study. The maximum body fat percentage was observed in group 5 (higher weight category) and minimum in group1 (lower weight) wrestlers.
} 


\section{Journal of Exercise Science \& Physiotherapy, Vol. 14, No. 1 (January to June), 2018 ISSN: 0973-2020 (Print) I I OR Impact Factor = 5.23 UGC Approved [no.7485] ISSN: 2454-6089 (Online)}

Thus, a trend of increased in body fat percentage from lower body weight group1 (46 kg- 50kg) to higher body weight group5 $(74 \mathrm{~kg})$ of wrestlers was observed. Saygin (2014) also reported a similar trend of body fat percentage of wrestlers that is the percentage body fat has different values in all three classes of wrestlers like lightweight, middle weight and heavy weight. According to Saygin (2014) the maximum body fat percentage was observed in heavyweight wrestlers as compared to lightweight wrestlers and middleweight wrestlers. In present study it was found that the push up score of the wrestlers of different groups was in the excellent range when compared with norms reported by Nieman (1995). Nieman (1995) reported the push-up norms for male age ranged 15 19 years like $39+$ follow in excellent, 29-38 above average, 23-28 average, 18-22 below average and less than 17 poor push up score completed by a subjects. The push up score of group1 (50 kg) weight categories wrestlers were more than the wrestlers of other groups of junior free style wrestlers. In present study pushups scores were negatively correlated with \%body fat of junior free style wrestlers. Johnson and Nelson (1979) reported that push-up scores were negatively correlated with the body weight and \% body fat of the subjects tested and similar results were also found in the present study. Brunet et al. (2007) observed a relationship between body composition and muscular endurance found negatively. Bovet et al. (2007) found a strong inverse relationship between fitness and excess body weight in youngsters. Esco et al. (2010) studied the relationship between selected anthropometric variables and push-ups tests and reported that muscular endurance test was negatively correlated with body mass index. Huang and Malina (2010) studied the relationship between four components of physical fitness including endurance and found that high body mass index was associated with poorer performance in the endurance test. According to Truter et.al., (2010) studied that normal weight categories subjects were more muscular endurance test, push up and sit up score as compared to obese and overweight subjects and negative correlation was found between muscular endurance test push up and anthropometric variables.

\section{Conclusion}

From the results of the present study, it is concluded that the body fat percentage of the wrestlers of different groups was in the acceptable range i.e. obesity was not observed in them. Further, it is concluded that the wrestlers of lower body weight category (group1) were better in anthropometric variables than higher body weight category wrestlers (group 5) like body fat percentage. Push-ups score was also observed better in the wrestlers of lower body weight category (group1) as compared to higher body weight category (group 5) junior free style wrestlers. A percentage body fat was also observed negative relationship related with push-ups. The push up score of the wrestlers of different groups was in the excellent range. So the \% body fat was found much effected on muscular endurance in our study.

\section{References}

Armstrong MEG, Lambert MI, Sharwood KA, Lambert EV. (2006) Obesity and overweight in South African primary school children - the Health of the Nation Study. JEMDSA 11(2):52-63.

Asker Jeukendrup and Michael Gleeson. (2010). Normal ranges of body weight and body fat: In Sport- An Introduction to Energy Production and Performance Nutrition, Chapter 13, 2nd Edition, Human Kinetics.

Bovet, P., R. Auguste, and H. Burdette, (2007) Strong inverse association between physical fitness and overweight in adolescents: a large school-based survey. Int J Behav Nutr Phys Act, .4: p. 24.

Brunet, M., J.P. Chaput, and A. Tremblay, (2007) The association between low physical fitness and high body mass index or waist circumference is increasing with age in children: the 'Quebec en Forme' Project.Int J Obes, .31(4): p. 637-43.

Durnin JV and Womersley J (1974).Body fat assessed from total body density and its estimation from skinfold thickness: measurements on 481 males and females aged from 16 to 72 years. Br J Nutr, 32:77-97.

Esco, M.R., M.S. Olson, and H.N. Williford, (2010) The relationship between selected body composition variables and muscular endurance in women. Res Q Exerc Sport,.81(3): p. 272-7. 
Franchini Emerson, Katarzyna Sterkowicz-Przybycien and Monica Yuri Takito (2014) Anthropometrical Profile of Judo Athletes: Comparative Analysis between Weight Categories. Int. J. Morphol., 32(1):36-42.

Gallagher, E. C. (1951). Wrestling (Revised Edition ed.). New York: The Ronald Press Company.

Horswill C.A. (1992). Applied physiology of amateur wrestling.Sports Med 14:114-143.

Huang, Y.C. and R.M. Malina, Body mass index and individual physical fitness tests in Taiwanese youth aged 9-18 years. Int J Pediatr Obes, 2010. 5(5): p. 404-11.

HubnerWozniak E., Kosmol A., Lutoslawska G., Bem E.Z. (2004).Anaerobic performance of arms and legs in male and female free style wrestlers. J Sci Med Sport 7:473-480.

Johnson L Barry, Nelson K Jack. Practical Approach to Measurement in Physical Education Philadelphia: Lea and Febiger. 1979.

Kraemer W.J., Fry AC, Rubin M.R., Triplett-mcbride T., Gordon S.E., Koziris L.P., Lynch J.M., Volek J.S., Meuffels D.E., Newton R.U., Fleck S.J. (2001) Physiological and performance responses to tournament wrestling. Med Sci Sports Exerc 33:1367-1378.

Nieman, D.C. (1995) Fitness and Sports Medicine, a Health Related Approach (3rd Edition). Mayfield Publishing Company, Mountain View, California.

Saygin.O (2014) Examination of Some Physical, Hematological Parameters and Iron Status of Greco-Roman Wrestlers in the Age Category of Cadets by Weight Classes Anthropologist 18(2): 325-334.

Sharratt M.T., Taylor A.W., Song T.M. (1986). A physiological profile of elite Canadian freestyle wrestlers. Can J Appl Sport Sci 11:100-105.

Steen, S. N., \& Brownell, K. D., (1990). Patterns of weight loss and regain in wrestlers: has the tradition changed. Med Sci Sports Exercise, 22(6), 762-768.

Truter L, a Pienaar AE, b Du Toit D. (2010) Relationships between overweight, obesity and physical fitness of nine- to twelve-year-old South African children. South African Family Practice, 52:3, 227-233, DOI: 10.1080/20786204.2010.10873979.

Truter L, a Pienaar AE, b Du Toit D. (2010) Relationships between overweight, obesity and physical fitness of nine- to twelve-year-old South African children. South African Family Practice, 52:3, 227-233, DOI: 10.1080/20786204.2010.10873979.

Yoon J. (2002). Physiological profiles of elite senior wrestlers. Sports Med 32:225-233.

Conflict of Interest: None declared 